\title{
Benzylideneacetophenone derivatives attenuate IFN- $\gamma$-induced IP-10/CXCL10 production in orbital fibroblasts of patients with thyroid-associated ophthalmopathy through STAT-1 inhibition
}

\author{
Sung-Hee Lee ${ }^{1,2}$, Seul Ye Lim ${ }^{1,2}$, Ji Ha Choi ${ }^{2,3}$, Jae-Chul Jung ${ }^{2,4}$, Seikwan Oh ${ }^{2,4}$, Koung Hoon Kook \\ and Youn-Hee Choi ${ }^{1,2}$
}

The aim of the present study was to identify a new candidate anti-inflammatory compound for use in the active stage of thyroidassociated ophthalmopathy (TAO). Benzylideneacetophenone compound JC3 [(2E)-3-(4-hydroxy-3-methoxyphenyl)phenylpro-2en-I-one] was synthesized based on a structural modification of yakuchinone B, a constituent of the seeds of Alpinia oxyphylla, which belongs to the ginger family (Zingiberaceae), has been widely used in folk medicine as an anti-inflammatory phytochemical. Orbital fibroblasts were primarily cultured from patients with TAO, and the potential of JC3 to suppress the interferon (IFN)- $\gamma$-induced protein (IP)-10/CXCL10 production in these cells was determined. IFN- $\gamma$ strongly increased the level of IP-10/CXCL10 in orbital fibroblasts from patients with TAO. JC3 exerted a significant inhibitory effect on the IFN- $\gamma$-induced increase in IP-10/CXCL10 in a dose-dependent manner; its potency was greater than that of an identical concentration of yakuchinone B with no toxicity to cells at the concentration range used. Moreover, the constructed dimer and trimer polystructures of JC3, showed greater potency than JC3 in suppressing the IFN- $\gamma$-induced production of IP-10/CXCL10. JC3 significantly attenuated the IP-10/CXCL10 mRNA expression induced by IFN- $\gamma$, and a gel-shift assay showed that JC3 suppressed IFN- $\gamma$-induced DNA binding of signal transducer and activator of transcription-1 (STAT-1) in TAO orbital fibroblasts. Our results provide initial evidence that the JC3 compound reduces the levels of IP-10/CXCL10 protein and mRNA induced by IFN- $\gamma$ in orbital fibroblasts of TAO patients. Therefore, JC3 might be considered as a future candidate for therapeutic application in TAO that exerts its effects by modulating the pathogenic mechanisms in orbital fibroblasts.

Experimental \& Molecular Medicine (2014) 46, e100; doi:10.1038/emm.2014.26; published online 13 June 2014

Keywords: benzylideneacetophenone; CXCL10/IP-10; IFN- $\gamma$; orbital fibroblasts; thyroid-associated ophthalmopathy; yakuchinone B

\section{INTRODUCTION}

Thyroid-associated ophthalmopathy (TAO) is an ophthalmic component of Graves' disease, which is caused by the production of stimulating autoantibody to the thyrotropin receptor. Symptoms of TAO include not only cosmetic deficits such as lid swelling, proptosis and lid retraction, but also functional deficits, such as limited ocular movement, which result in diplopia, and even visual loss.
Although the pathogenic mechanism of TAO is not fully understood, inflammation dominates the early pathology of the disease. In the active stage, some immunocompetent cells, such as T and B lymphocytes, plasma cells and macrophages infiltrate the orbital tissues, including the orbital fat and extraocular muscles. ${ }^{1,2}$ In addition, the mRNA levels of several proinflammatory cytokines, including interleukin (IL) $-1 \beta$ and interferon (IFN)- $\gamma$, are increased in the affected

\footnotetext{
${ }^{1}$ Department of Physiology and Global Top5 Research Program, Ewha Woman's University School of Medicine, Seoul, Korea; ${ }^{2}$ Tissue Injury Defense Research Center, Ewha Woman's University School of Medicine, Seoul, Korea; ${ }^{3}$ Department of Pharmacology, Ewha Woman's University School of Medicine, Seoul, Korea; ${ }^{4}$ Department of Neuroscience, Ewha Woman's University School of Medicine, Seoul, Korea and ${ }^{5}$ Department of Ophthalmology, Ajou University School of Medicine, Suwon, Korea

Correspondence: Dr KH Kook, Department of Ophthalmology, Ajou University School of Medicine, World Cup-Road 164, Woncheon-dong, Yeongtong-gu, Suwon 443-721, Korea.

E-mail: drkook@ajou.ac.kr

or Professor Y-H Choi, Department of Physiology and Global Top5 Research Program, Ewha Woman's University School of Medicine, 911-1 Mok-dong, Yangcheon-gu, Seoul 158-710, Korea.

E-mail: yc@ewha.ac.kr
}

Received 21 October 2013; revised 9 January 2014; accepted 13 January 2014 
orbital tissues. ${ }^{3,4}$ Orbital fibroblasts that are abundant in orbital fatty connective tissues are currently believed to be the key cells in the modulation of the immunologic process of TAO, which results in active inflammation. ${ }^{5}$ When activated by IL- $1 \beta$ or IFN- $\gamma$, orbital fibroblasts express high levels of IL-6, prostaglandin E2 and major histocompatibility complex class II. ${ }^{6-8}$

C-X-C motif chemokine 10 (CXCL10), also known as IFN- $\gamma$-induced protein 10 (IP-10), is a non-ELR (Glu-LeuArg) CXC chemokine first cloned in 1985 as a protein produced by peripheral blood mononuclear cells, fibroblasts and endothelial cells via induction by IFN $-\gamma \cdot{ }^{9}$ Expression of the IP-10/CXCL10 gene is known to be regulated by several putative transcription factors, such as NF- $\kappa \mathrm{B}, \mathrm{AP}-1$ and signal transducer and activator of transcription (STAT), the activation of which is induced by IFN- $\gamma$ through selective phosphorylation by Janus kinase. ${ }^{10-12}$ IP-10/CXCL10 is expressed in a variety of chronic inflammatory and autoimmune disorders, including thyroid disease. ${ }^{13-17}$ Because thyrocytes secrete IP-10/CXCL10 upon IFN- $\gamma$ stimulation, which in turn recruits $\mathrm{T}_{\mathrm{H}} 1$ lymphocytes expressing CXCR3 and secreting IFN- $\gamma$, IP-10/CXCL10 and its receptor CXCR3 are thought to have an important role in the initiation of autoimmune thyroid disorders, and so this chemokine system could be a new therapeutic target in such diseases. ${ }^{17,18}$ Although little is known about the relevance of IP-10/ CXCL10 and TAO, IP-10/CXCL10 levels are significantly increased in the serum of patients with TAO, particularly in the active stage, and orbital fibroblasts from patients with TAO produce IP-10/CXCL10 via stimulation by IFN- $\gamma .{ }^{19}$ Taken together, these findings indicate that the IP-10/CXCL10 system could be a candidate-specific therapeutic target in the pathogenesis of TAO that acts by attenuating active inflammation.

Yakuchinone B, a constituent of the seeds of Alpinia oxyphylla, which belongs to the ginger family (Zingiberaceae), has been commonly used in folk medicine. ${ }^{20}$ According to several studies, yakuchinone B is known to have significant biological effects such as anti-inflammatory, ${ }^{21}$ antitumor $^{22}$ and antiviral $^{23}$ activities. JC1 to JC5 are benzylideneacetophenone derivatives that were synthesized based on a structural modification of yakuchinone B in previous efforts to develop neuroprotective agents. These derivatives showed beneficial effects in neurodegenerative diseases, suggesting the efficacy of these compounds as therapeutic agents for particular diseases. ${ }^{24}$

This study is the first to evaluate the possibility of the therapeutic application of yakuchinone B and its synthetic derivatives in the treatment of TAO. We herein demonstrate that JC3, a yakuchinone B derivative, significantly attenuates the IFN- $\gamma$ induced IP-10/CXCL10 expression in orbital fibroblasts from patients with TAO and that this inhibitory effect is mediated, at least in part, by the suppression of STAT-1 activation.

\section{MATERIALS AND METHODS}

\section{Cell culture}

Human orbital fibroblasts were cultured from orbital fatty connective tissue obtained as a surgical waste during decompression surgery for patients with TAO or during orbital surgery for a patient without TAO to resolve a noninflammatory condition, as described previously. ${ }^{25}$ These activities were undertaken after informed consent was obtained from the donors according to procedures approved by the Institutional Review Board of Ajou University Hospital and following the tenets of the Declaration of Helsinki. All patients with TAO had experienced at least 6 months of inactive disease with a euthyroid condition prior to the decompression surgery. Once obtained, cells were maintained in Dulbecco's modified essential medium (Welgene Inc., Daegu, Korea) containing 10\% (vol/vol) fetal bovine serum (HyClone, North Logan, UT, USA) and antibiotics in a humidified $5 \% \mathrm{CO}_{2}$ incubator at $37^{\circ} \mathrm{C}$. Cells in passages three to eight were used in the present study.

\section{Compound synthesis}

The synthesis of benzylideneacetophenone derivatives was initiated as described previously. ${ }^{24}$ The 4-hydroxy-3-methoxy cinnamaldehyde was protected with tert-butyldimethylsilyl trifluoromethanesulfonate in the presence of 2,6-lutidine or 2-(trimethylsilyl) ethoxymethyl chloride (SEM-Cl)/N,N-di-isopropylethylamine to form aldehydes with 95 and 97\% yields, respectively. Benzylideneacetophenone compound (JC3) was fully identified by infrared and NMR spectroscopy, including high-resolution mass spectroscopy. In addition, dimers (JC3-D) and trimers (JC3-T) of JC3 were constructed to evaluate the efficacy of polystructures of JC3 (Figure 1).

\section{Enzyme-linked immunosorbent assay (ELISA)}

IP-10/CXCL10 protein levels were measured in culture supernatants of orbital fibroblasts seeded in six-well culture plates at a final concentration of $5 \times 10^{4}$ per well. After stabilization for $16 \mathrm{~h}$, cells were treated with stimulatory factors, including IFN- $\gamma$ (ProSpec, Rehovot, Israel), lipopolysaccharides (LPS) (Sigma-Aldrich Co., St Louis, MO, USA), IL-1 $\beta$ (BioSource, Camarillo, CA, USA) and $\mathrm{H}_{2} \mathrm{O}_{2}$ (Sigma-Aldrich Co.). In some experiments, cells were co-treated by adding the benzylideneacetophenone compound, as described. After treatment for $24 \mathrm{~h}$, supernatant IP-10/CXCL10 concentrations were determined by a sandwich ELISA method with human IP-10 BD OptEIA (BD Biosciences, Franklin Lakes, NJ, USA) according to the manufacturer's instructions. Briefly, 96-well plates were precoated overnight at room temperature with a capture antibody. After three washes, plates were blocked with phosphate-buffered saline $(\mathrm{pH} 7.4)$ containing 5\% (wt/vol) skim milk (BD Biosciences) followed by
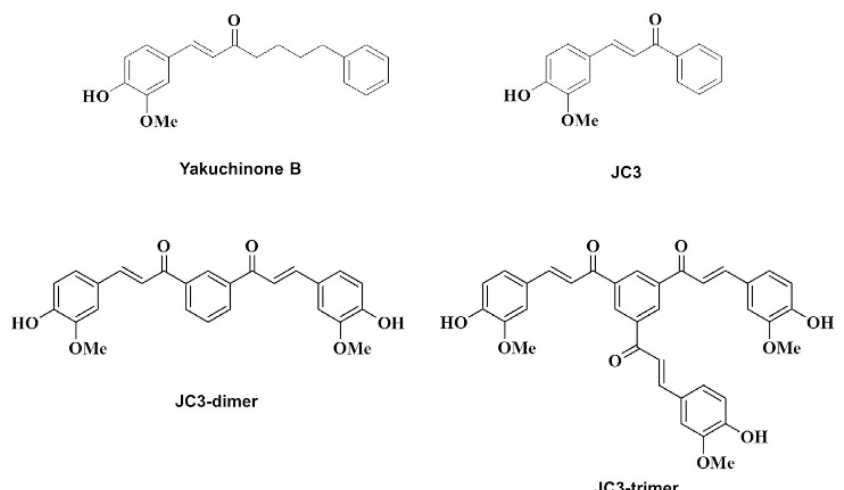

Figure 1 Structures of yakuchinone B; JC3, which was synthesized based on a structural modification of yakuchinone $B$; and constructed polystructures of JC3 (JC3 dimer and JC3 trimer). 
incubation with a detection antibody. After washing, the plates were incubated with horseradish peroxidase-conjugated secondary antibody for $1 \mathrm{~h}$ and then incubated with the BD OptEIA TMB substrate reagent set (BD Bioscience) (reagent A: substrate, $\mathrm{H}_{2} \mathrm{O}_{2}$ and reagent $\mathrm{B}$ : tetramethylbenzidine) for $30 \mathrm{~min}$. Absorbance was measured spectrophotometrically at $540 \mathrm{~nm}$ using a microplate reader. The concentration of IP-10/CXCL10 in each sample was determined by referencing a standard curve generated using known amounts of IP-10/CXCL10.

\section{Reverse transcription-PCR (RT-PCR)}

Total cellular RNA was isolated from a confluent monolayer of cells using easy-BLUE (iNtRON Biotechnology, Seongnam, Korea) according to the manufacturer's protocol. cDNA was synthesized from $1 \mu \mathrm{g}$ of total RNA with reverse transcription, and PCR was performed using $3 \mu \mathrm{l}$ of cDNA. The primer sequences were as follows. Human IP-10: forward, 5'-GTA CCT CTC TCT AGA ACC GTA CG-3' and reverse, $5^{\prime}$-CCT TTA CAG ATT TTC TAG AG-3'; GAPDH: forward, $5^{\prime}$-GTC AGT GGT GGA CCT GAC CT-3' and reverse, 5' ${ }^{\prime}$-TGT GAG GAG GGG A GA TTC AG-3'. mRNA expression values were normalized to GAPDH mRNA levels for each experimental condition.

\section{Cytotoxicity assay}

Cell growth and death were assessed using WST-8-[2-(2-methoxy-4nitrophenyl)-5-(2,4-disulfophenyl)-2 H-tetrazolium monosodium salt] (Cell Counting Kit 8 (CCK-8); Dojindo Molecular Technology Inc., Kumamoto, Japan). Orbital fibroblasts $\left(1 \times 10^{4}\right)$ were seeded into 24-well culture plates and co-treated with IFN- $\gamma$ and benzylideneacetophenone compound at 5,10 and $20 \mu \mathrm{M}$. Following $24 \mathrm{~h}$ of treatment, CCK- 8 solution ( $1 / 10 \mathrm{vol} / \mathrm{vol}$ in serum-free media) was added to each well, and the plates were incubated for $3 \mathrm{~h}$ at $37^{\circ} \mathrm{C}$. Finally, absorbance at $450 \mathrm{~nm}$ was determined using a microplate reader.

\section{Electrophoretic mobility shift analysis (EMSA)}

EMSA was performed with $1 \mu \mathrm{g}$ of nuclear extracts as described previously. ${ }^{11}$ Nuclear extracts from orbital fibroblasts treated with IFN- $\gamma$ in the presence or absence of the benzylideneacetophenone compound JC3 for 30 min were incubated with either the consensus NF- $\kappa \mathrm{B}$ sequence (forward, 5'-AGTTGAGGGACTTTCCCAGGC-3' and reverse, $5^{\prime}$-TCCTGGGAAAGTCCCCTCAACT- $3^{\prime}$ ) or the STAT-1 sequence (SC-2573; Santa Cruz Biotechnology, Santa Cruz, CA, USA), which was end-labeled with $\left[{ }^{32} \mathrm{P}\right]$ ATP. For competition and supershift experiments, a 100-molar excess of unlabeled oligonucleotide or $1 \mu \mathrm{g}$ of anti-STAT-1, -p50 or -p65 antibodies was added to the nuclear extracts for $30 \mathrm{~min}$ before addition of the labeled probe. Bound and free DNA were then resolved by electrophoresis in a $6 \%$ polyacrylamide gel and exposed for autoradiography.

\section{Statistical analysis}

Statistical analyses were performed using Student's $t$-test for comparisons between sample groups, and analysis of variance was used to determine the differences among multiple groups. The SPSS 15.0 software (SPSS Inc., Chicago, IL, USA) was used for analysis, and the statistical significance of differences was set at $P<0.05$.

\section{RESULTS}

IFN- $\gamma$ strongly induces IP-10/CXCL10 in orbital fibroblasts Serum levels of IP-10/CXCL10 are increased in patients with $\mathrm{TAO}$, particularly in the active stage of the disease, and orbital fibroblasts can produce IP-10/CXCL10. ${ }^{19}$ Thus, we initially examined the effects of IFN- $\gamma$ as well as LPS, IL- $1 \beta$ and $\mathrm{H}_{2} \mathrm{O}_{2}$, which are known as inflammatory stimulants, on IP-10/ CXCL10 levels in human orbital fibroblasts from patients with TAO and a subject without TAO. Cells were treated with each stimulant (IFN- $\gamma$ at $10 \mathrm{ng} \mathrm{ml}^{-1}$, LPS at $100 \mathrm{ng} \mathrm{ml}^{-1}$ and IL- $1 \beta$ at $10 \mathrm{ng} \mathrm{ml}^{-1}$ ) for $24 \mathrm{~h}$ and $\mathrm{H}_{2} \mathrm{O}_{2}$ at $100 \mu \mathrm{m}$ for $30 \mathrm{~min}$. IP-10/CXCL10 protein levels in culture supernatants were then determined by ELISA as described in the Materials and Methods section. In response to IFN- $\gamma$, the IP-10/CXCL10 protein level had most strikingly increased in cells from the patients with TAO $(n=2)$ and the subject without TAO $(n=1)$. IL-1 $\beta$ also significantly increased the level of IP-10/ CXCL10 expression, but to a notably lesser degree than did IFN- $\gamma$. When treated with LPS, one TAO cell strain did not show an increase in IP-10/CXCL10 protein (Figure 2).

\section{Yakuchinone B and JC3 attenuate IFN- $\gamma$-induced IP-10/ CXCL10 expression in orbital fibroblasts without influencing cell viability}

To examine the effects of the JC3, benzylideneacetophenone compound modified from yakuchinone B (Figure 1), on IFN$\gamma$-induced IP-10/CXCL10 expression, orbital fibroblasts from patients with TAO were pretreated with incremental doses of JC3 for $30 \mathrm{~min}$ and then stimulated with IFN- $\gamma\left(10 \mathrm{ng} \mathrm{ml}^{-1}\right)$ for $24 \mathrm{~h}$. JC3 showed dose-dependent inhibition of IFN- $\gamma$ induced IP-10/CXCL10 protein expression, and a significant reduction was observed at a dose of $10 \mu \mathrm{M}$ in orbital fibroblasts from patients with TAO and at doses of 5 and $10 \mu \mathrm{m}$ in the

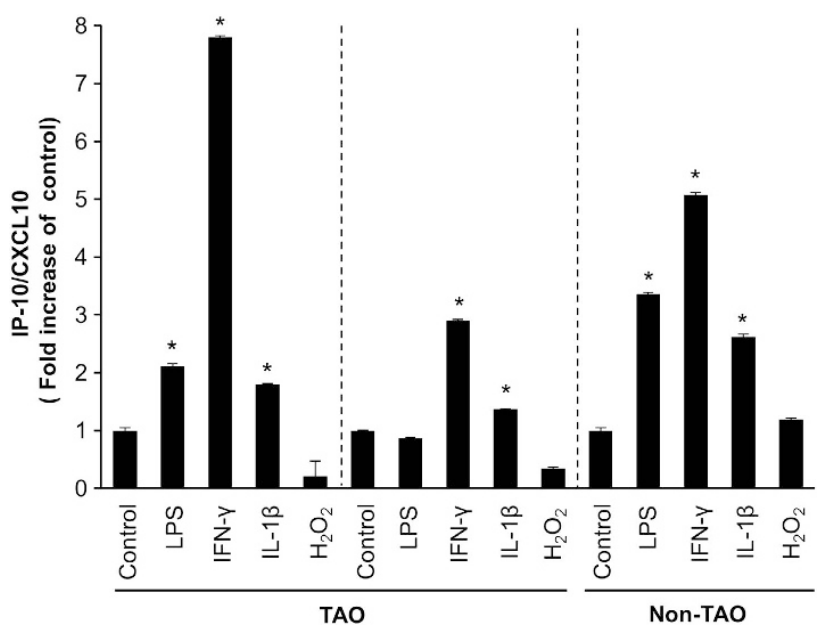

Figure 2 IFN- $\gamma$ increases IP-10/CXCL10 levels in orbital fibroblasts. Primary cultures of orbital fibroblasts $\left(5 \times 10^{4}\right)$ of patients with TAO $(n=2)$ and a subject without TAO $(n=1)$ were incubated with IFN- $\gamma\left(10 \mathrm{ng} \mathrm{ml}^{-1}\right)$, LPS $\left(100 \mathrm{ng} \mathrm{ml}^{-1}\right)$ and IL-1 $\beta$ $\left(10 \mathrm{ng} \mathrm{ml}^{-1}\right)$ for $24 \mathrm{~h}$ and $\mathrm{H}_{2} \mathrm{O}_{2}(100 \mu \mathrm{m})$ for $30 \mathrm{~min}$. After treatment, supernatants were collected and IP-10/CXCL10 protein levels in each culture supernatant were measured by ELISA. Data are presented as the fold increases in relative IP-10/CXCL10 levels from orbital fibroblasts compared with each control. The graph shows the mean \pm s.d. of three independent replicates $\left({ }^{*} P<0.05\right.$ vs each untreated control). 
subject without TAO. At $20 \mu \mathrm{M}$ of JC3, the value of IP-10/CXCL10 protein was below the limit of detection of the assay in all cell strains (Figure 3a). Although $10 \mu \mathrm{M}$ yakuchinone B effectively suppressed IFN- $\gamma$-induced IP-10/ CXCL10 expression in orbital fibroblasts from patients with $\mathrm{TAO}$, the same dose of JC3 showed stronger potency in attenuating the IFN- $\gamma$-induced IP-10/CXCL10 increase than did yakuchinone B (Figure $3 \mathrm{~b}$ ). To determine whether JC3 influences the viability of orbital fibroblasts from patients with TAO, a CCK-8 assay was performed to assess the toxicity of the JC3 compound. As shown in Figure 3c, the viability of primary orbital fibroblasts was not affected by 24-h incubation with JC3 compound at a concentration of up to $20 \mu \mathrm{M}$.

Polystructure-dependent potency of JC3 in attenuating IFN$\gamma$-induced IP-10/CXCL10 expression in orbital fibroblasts from patients with TAO

Orbital fibroblasts from patients with TAO were incubated with incremental doses of JC3-D $(0.1-10 \mu \mathrm{M})$ or JC3-T
$(0.1-10 \mu \mathrm{M})$ for $30 \mathrm{~min}$ followed by treatment with IFN- $\gamma$ $\left(10 \mathrm{ng} \mathrm{ml}^{-1}\right)$ for $24 \mathrm{~h}$. After treatment, the IP-10/CXCL10 level in the supernatant was measured by ELISA. As shown in Figures $4 \mathrm{a}$ and $\mathrm{b}$, the inhibitory effect of JC3 polystructures on the IFN- $\gamma$-induced IP-10/CXCL10 increase reached a significant level at $1 \mu \mathrm{M}$ dimers and $0.1 \mu \mathrm{M}$ trimers, respectively. The IFN- $\gamma$-induced increase in IP-10/CXCL10 was reduced by $10 \mu \mathrm{M}$ JC3 monomer (50\% reduction compared with IFN- $\gamma$ induced levels), and IFN- $\gamma$-mediated IP-10/CXCL10 protein levels were below the limit of detection with the same concentrations of dimers and trimers (Figure 4c). These results demonstrate that polystructures of JC3 exhibit stronger inhibitory effects on IP-10/CXCL10 expression in the orbital fibroblasts from patients with TAO.

\section{JC3 attenuates IFN- $\gamma$-induced IP-10/CXCL10 transcription} in orbital fibroblasts of patients with TAO

To determine whether JC3 affects expression at the transcriptional level, orbital fibroblasts from patients with TAO were treated with IFN- $\gamma\left(10 \mathrm{ng} \mathrm{ml}^{-1}\right)$ in the presence or
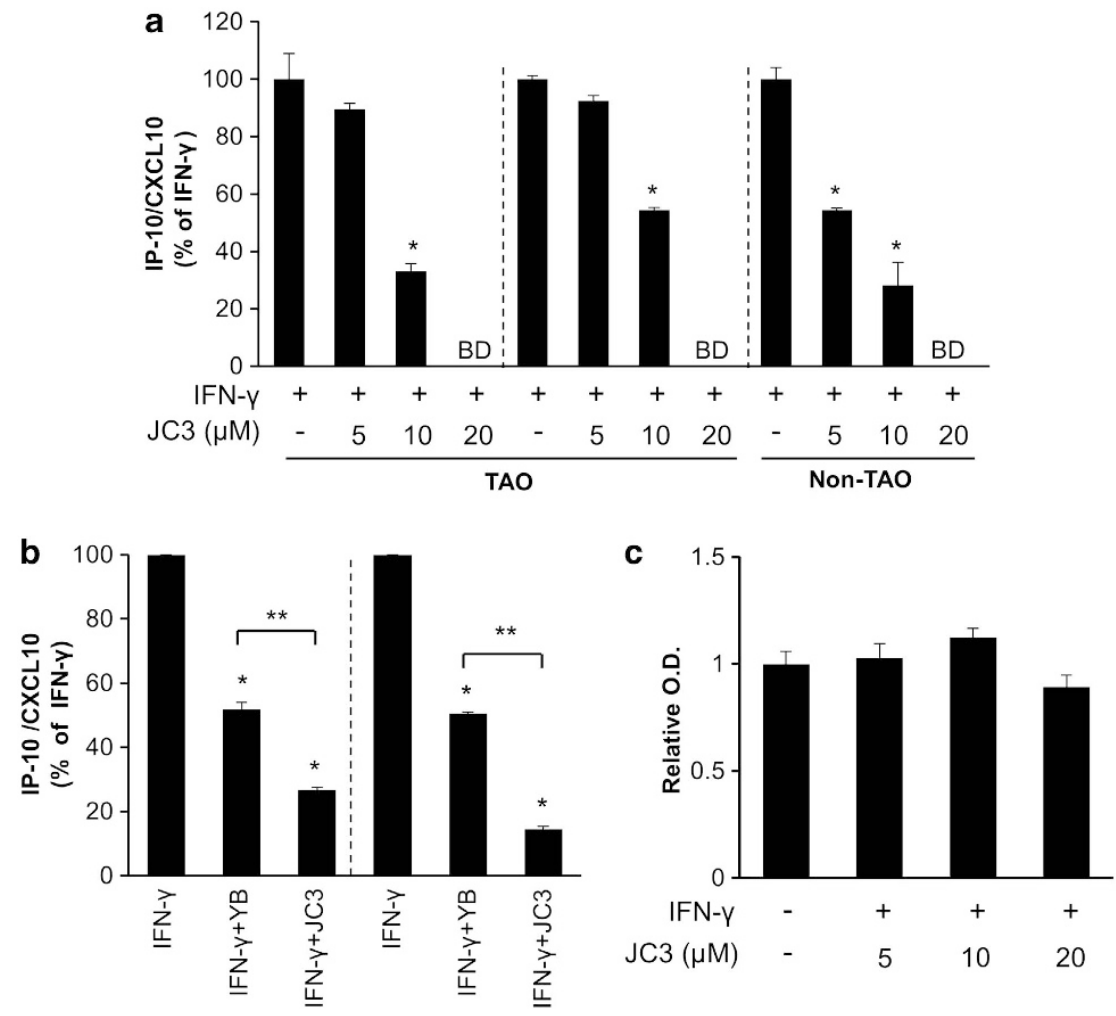

Figure 3 The IFN- $\gamma$-induced IP-10/CXCL10 level was attenuated by the benzylideneacetophenone derivative compound, JC3, in a dosedependent manner without an influence on the viability of orbital fibroblasts from patients with TAO. (a) TAO and non-TAO cells were pretreated with JC3 at 5, 10 and $20 \mu \mathrm{m}$ for 30 min and then treated with IFN- $\gamma\left(10 \mathrm{ng} \mathrm{ml}^{-1}\right)$ for $24 \mathrm{~h}$; the supernatant was then collected to measure IP-10/CXCL10 protein by ELISA. The IP-10/CXCL10 expression level in IFN- $\gamma$-treated group was arbitrarily assigned a value of 100 , and the data are presented as percentage reductions ( ${ }^{*} P<0.05$ vs each IFN- $\gamma$ group; BD, below detection limit). (b) TAO cells were pretreated with either yakuchinone B or JC3 at $10 \mu \mathrm{m}$ for $30 \mathrm{~min}$. Following treatment with IFN- $\gamma\left(10 \mathrm{ng} \mathrm{ml}{ }^{-1}\right)$ for $24 \mathrm{~h}$, IP-10/CXCL10 production was measured and analyzed as described in $\mathrm{A}\left({ }^{*} P<0.05\right.$ vs each IFN- $\gamma$-treated group; ${ }^{*} P<0.05$ in JC3-treated group vs yakuchinone B-treated group). (c) Orbital fibroblasts of patients with TAO patients were treated with IFN- $\gamma\left(10 \mathrm{ng} \mathrm{ml}^{-1}\right)$ in the presence or absence of 5, 10 of $20 \mu \mathrm{m} \mathrm{JC} 3$ for $24 \mathrm{~h}$. After treatment, cell viability was evaluated as described in the Materials and Methods section. Results are expressed as mean \pm s.d. in relative O.D. units (compared with control); normalized values are shown. 
a

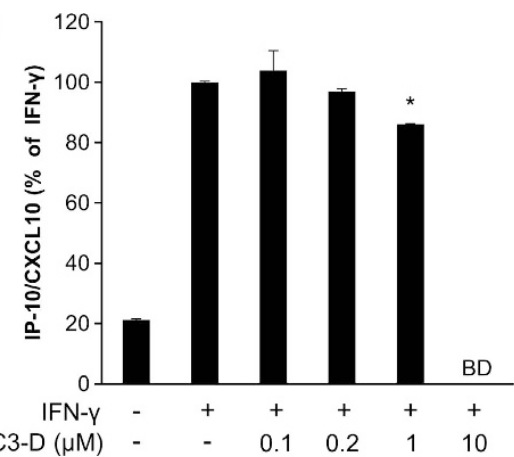

b

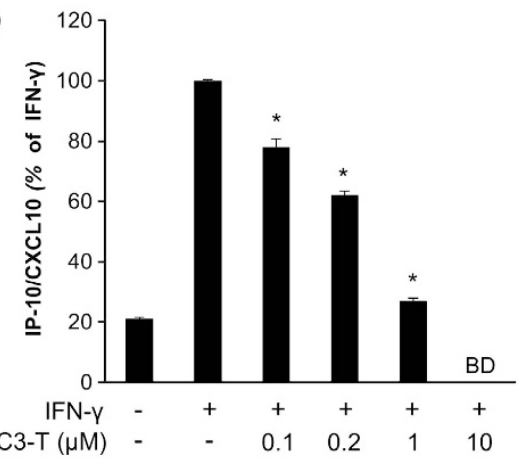

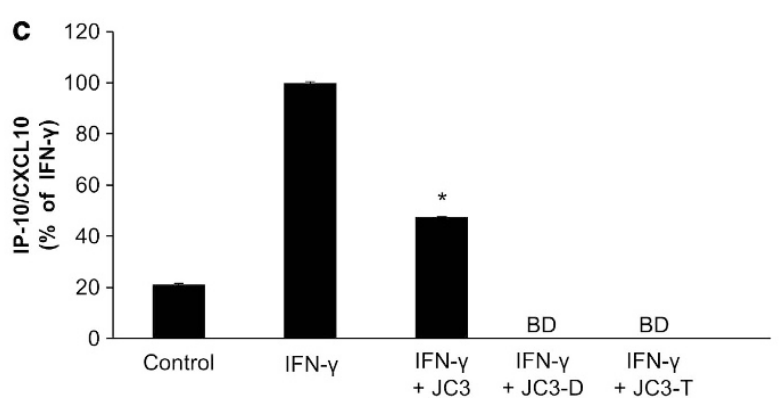

Figure 4 Polystructures of JC3 reveal an enhanced inhibitory effect of IFN- $\gamma$-induced IP-10/CXCL10 expression in orbital fibroblasts from patients with TAO patients. (a, b) Orbital fibroblasts from patients with TAO were treated with IFN- $\gamma\left(10 \mathrm{ng} \mathrm{ml}^{-1}\right.$ ) in the presence of

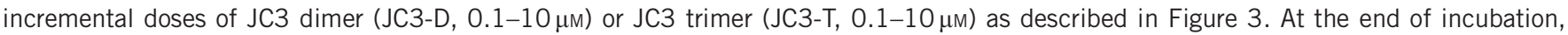
the supernatant was collected and analyzed by ELISA. (c) Cells were pretreated with $10 \mu \mathrm{m}$ of JC3, JC3-D, or JC3-T, and the IP-10/ CXCL10 level was assessed by ELISA. The IP-10/CXCL10 expression level of the IFN- $\gamma$-treated group was arbitrarily assigned a value of 100 , and data are presented as percentage reductions ( ${ }^{*} P<0.05$ vs IFN- $\gamma$-treated group; BD, below detection limit).

absence of JC3 $(10 \mu \mathrm{M})$ for $24 \mathrm{~h}$, and RNA was then extracted and subjected to RT-PCR. IFN- $\gamma$ increased the mRNA transcription of IP-10/CXCL10, and JC3 drastically suppressed the IFN- $\gamma$-induced increase in the IP-10/CXCL10 mRNA level (Figure 5). JC3 alone also showed suppression of the IP-10/ CXCL10 mRNA level. The expression level of GAPDH was not affected by either JC3 or IFN- $\gamma$ treatment.

\section{JC3 inhibits DNA binding of STAT-1 in orbital fibroblasts of patients with TAO}

Expression of the IP-10/CXCL10 gene is regulated by several transcription factors, such as NF- $\kappa \mathrm{B}, \mathrm{AP}-1$ and STAT- 1 , the activation of which is induced by IFN- $\gamma$. To investigate the inhibitory mechanism of JC3 on IP-10/CXCL10 transcription, the effect of JC3 on IFN- $\gamma$-induced DNA binding of STAT-1 and NF- $\kappa \mathrm{B}$ was examined. EMSA was performed using nuclear extracts from TAO orbital fibroblasts stimulated with IFN- $\gamma\left(10 \mathrm{ng} \mathrm{ml}^{-1}\right)$ in the absence or presence of JC3 $(10 \mu \mathrm{M})$ for $30 \mathrm{~min}$. As shown in Figure 6a, the DNA binding activity of STAT-1 had increased markedly in response to IFN- $\gamma$ (lane 4), and JC3 attenuated the increase (lane 5). As shown in Figure 6b, a remarkable amount of DNA-bound $N F-\kappa B$ was found in the untreated control (lane 2). IFN- $\gamma$ slightly enhanced the DNA binding of NF- $\kappa \mathrm{B}$ (lane 4), but
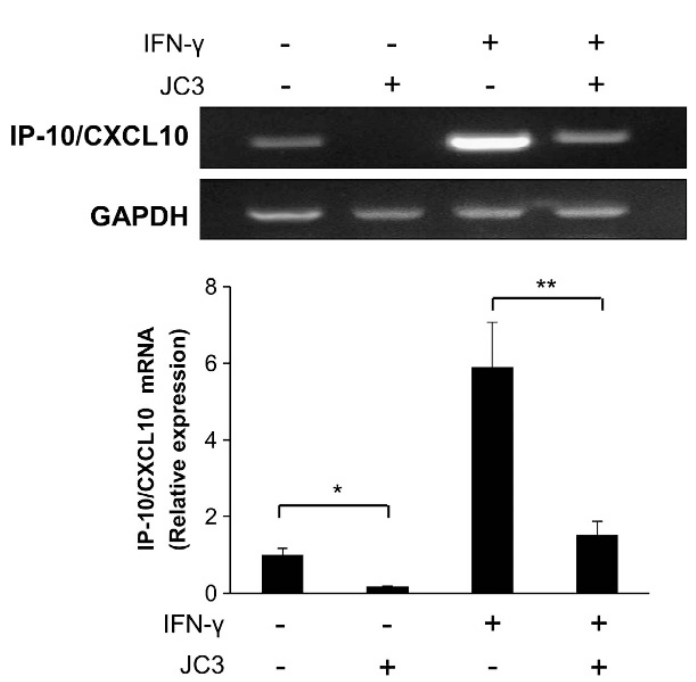

Figure $5 \mathrm{JC} 3$ reduced IFN- $\gamma$-induced IP-10/CXCL10 mRNA expression in TAO orbital fibroblasts. Total RNA was extracted after $24 \mathrm{~h}$ of IFN- $\gamma\left(10 \mathrm{ng} \mathrm{ml}^{-1}\right)$ treatment in the presence or absence of JC3. IP-10/CXCL10 mRNA levels were analyzed by RT-PCR. The control level of IP-10/CXCL10 expression was arbitrarily assigned a value of 1 . Data are means of three independent experiments. ${ }^{*} P<0.05$ and ${ }^{*} P<0.05$ compared with the untreated control and IFN- $\gamma$-treated group, respectively. 

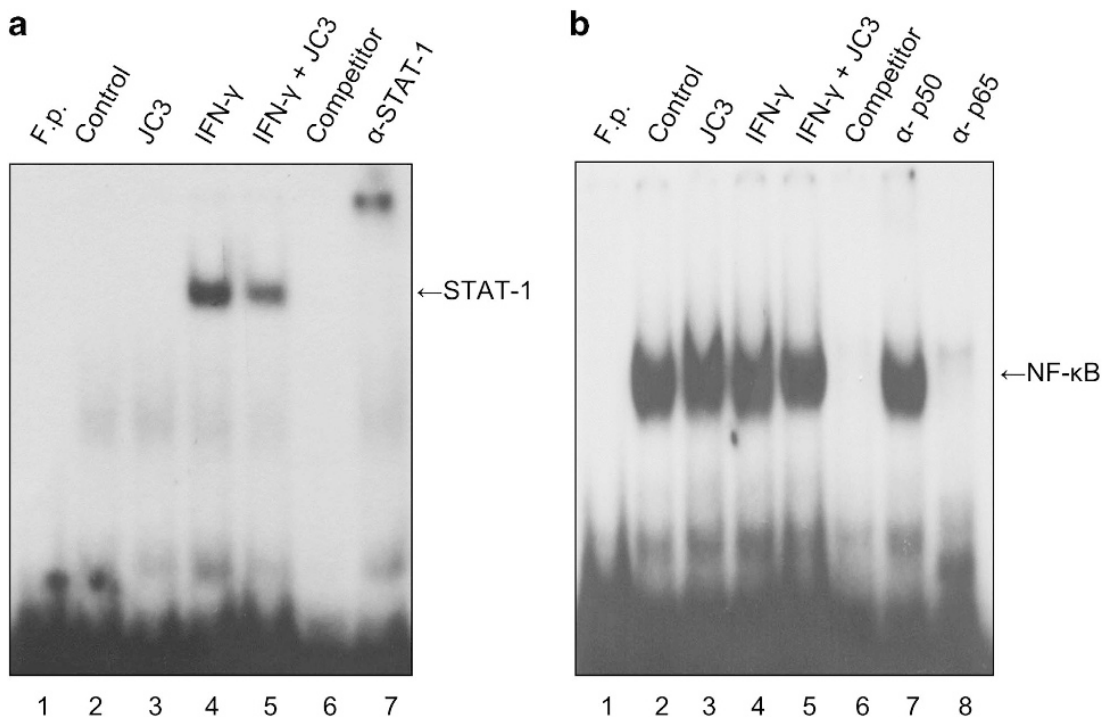

Figure 6 JC3 inhibited DNA binding of STAT-1, but not NFKB, in IFN- $\gamma$-stimulated TAO orbital fibroblasts. Cells were treated with IFN- $\gamma$ $\left(10 \mathrm{ng} \mathrm{ml}^{-1}\right)$ in the presence or absence of JC3 $(10 \mu \mathrm{m})$ for $30 \mathrm{~min}$, and nuclear extracts were prepared and analyzed by EMSA as described in the Materials and Methods section. The levels of (a) STAT-1 DNA binding and (b) p50/p65 NF- $\mathrm{kB}$ DNA binding were evaluated by EMSA. A cold probe was used for competition control. Data shown are representative of at least three independent experiments.

JC3 did not show an inhibitory effect (lane 5). The specific band was selectively inhibited by a specific STAT-1 competitor and supershifted by an anti-STAT-1 antibody. In the case of NF- $\kappa B$, DNA binding was diminished by an NF- $\kappa B$ competitor and supershifted by an anti-p-65, but not anti-p-50 antibody.

\section{DISCUSSION}

Results from this study showed that JC3, a benzylideneacetophenone compound modified from yakuchinone $\mathrm{B}$, exerted a strong inhibitory effect on IFN- $\gamma$-induced expression of IP-10/ CXCL10 at both the protein and mRNA level, without affecting the viability of orbital fibroblasts derived from patients with TAO. JC3 also attenuated the IFN- $\gamma$-induced binding of STAT- 1 to DNA in these cells. These results suggest that JC3 suppresses IFN- $\gamma$-induced IP-10/CXCL10 expression by attenuating the STAT- 1 signal transduction pathway in TAO orbital fibroblasts.

TAO is a component of Graves' disease, but no direct correlation between TAO and aberrant thyroid hormone levels has been found. ${ }^{5}$ Although the pathogenic mechanism of TAO has not been fully elucidated, it is commonly accepted that orbital fibroblasts have a key role in TAO development by modulating immune reactions that result in the active inflammation of orbital tissues. Unlike fibroblasts elsewhere in the human body, orbital fibroblasts display surface expression of CD40. They also express several inflammatory cytokines, including IL-6, IL-8 and macrophage chemoattractant protein-1, and show an exaggerated response to several proinflammatory cytokines including IFN- $\gamma .^{26,27}$ In addition, several inflammatory cytokines/chemokines, such as IP-10/CXCL10, are thought to have a major role in the pathogenesis of TAO. ${ }^{28}$ The observed increase of IP-10/ CXCL10 was also more pronounced in the early phase of TAO with active inflammation as compared with the late phase. These results showing increased levels of IP-10/CXCL10 induced by IFN $-\gamma$ in orbital fibroblasts from TAO patients are in agreement with a previous report of $\mathrm{T}_{\mathrm{H}} 1$ cytokine involvement in both Graves' disease and TAO. ${ }^{29}$

With respect to treatment, effective attenuation of early inflammation in the active stage of TAO is important for controlling its progression, because the severity of early phase inflammation influences the extent of fibrotic changes in the late phase, which can result in irreversible deficits. ${ }^{30}$ Although corticosteroids have been utilized as first-line drugs for patients in the active stage of TAO owing to their strong immunosuppressive effects, serious side effects have limited their clinical application. ${ }^{28}$ Therefore, efforts have focused on the search for novel targeted anti-inflammatory drugs that are associated with fewer adverse events.

Yakuchinone B is a constituent of seeds from A. oxyphylla, a member of the ginger family (Zingiberaceae) commonly used in folk medicine. It shows a variety of biological effects including anti-inflammatory activity, ${ }^{20}$ as demonstrated by its strong inhibitory effect on prostaglandin biosynthesis in vitro. ${ }^{31}$ Like curcumin, yakuchinone $\mathrm{B}$ has a diarylheptanoid moiety with a carbonyl functional group that is known to possess strong anti-oxidative and anti-inflammatory activities. ${ }^{32}$ One author of the current study (S. Oh) previously designed and synthesized novel benzylideneacetophenone derivatives (JC1 to JC5) on the basis of the structure of yakuchinone $\mathrm{B}$, and showed that they exert a protective effect on brain ischemia both in vitro and in vivo. ${ }^{33}$ In the present investigation, all compounds synthesized in this series (JC1 to 
JC5) showed considerable suppression of IFN- $\gamma$-induced IP-10/CXCL10 expression in orbital fibroblasts (data not shown). JC3, however, showed the greatest inhibitory effect, suppressing IFN- $\gamma$-induced IP-10/CXCL10 expression to a greater extent than yakuchinone B (Figure $3 \mathrm{~b}$ ). The greater efficacy of JC3 is likely related to its structural characteristics; it is inherently stable due to electron delocalization, and likely engages in hydrogen bonding with its receptor-binding site (the benzylideneacetophenone derivative) to exert its potent inhibitory effect. Polystructures of JC3 compounds (JC3 dimer and JC3 trimer) also suppressed IFN- $\gamma$-induced IP-10/CXCL10 expression in orbital fibroblasts with greater potency than JC3 monomers, suggesting that the structure of JC3 is critical for suppression of IFN- $\gamma$-induced IP-10/CXCL10 expression.

In a previous report, JC3 exerted a number of effects in activated microglia through suppression of the Janus kinase/ STAT and MAPK signaling pathways. These include modulation of LPS-induced NO generation, iNOS gene expression, proinflammatory cytokine expression and reactive oxygen species generation. ${ }^{34}$ In orbital fibroblasts from patients with TAO, JC3 inhibited IFN- $\gamma$-induced IP-10/CXCL10 expression, primarily through suppression of STAT-1 pathways (Figure 6a). Expression of the IP-10/CXCL10 gene is regulated by several putative transcription factors, including NF- $\kappa$ B and STAT-1 (the activation of which is induced by IFN$\gamma)$. DNA binding of NF- $\kappa B$ in IFN- $\gamma$-stimulated TAO orbital fibroblasts was not affected by JC3 in our system, suggesting that the major target of JC3 in IFN- $\gamma$-induced IP-10/CXCL10 expression is the STAT-1-mediated pathway. However, the inhibitory effect of JC3 on STAT-1 activity was relatively incomplete. This suggests the existence of other pharmacological activities of JC3 for attenuating IFN- $\gamma$-induced IP-10/ CXCL10 production in orbital fibroblasts, in addition to the STAT-1-dependent mechanism. In cell types other than orbital fibroblasts, C/EBP- $\beta$ and AP-1 are also involved in IFN- $\gamma$-induced IP-10/CXCL10 expression. ${ }^{35}$ Therefore, it will be interesting to examine the effect of JC3 on these transcription factors.

In our system, we performed the experiment using primary cells from patients with TAO. Unfortunately, the current lack of an effective animal model displaying the known characteristics of TAO represents a fundamental limitation in this field of research. A number of studies have examined the cellular characteristics of orbital fibroblasts cultured from primary cells obtained in TAO patients, ${ }^{36-38}$ but results from these in vitro studies should be interpreted with caution when applied toward any clinical investigation. However, our experimental model using a primary cell culture system could be a preliminary step for investigating the cellular effects of potential therapies to be developed for the treatment of TAO disease. Although we could not include in vivo experiments in this study, one author of this study (S. Oh) previously showed the anti-inflammatory and neuroprotective effects of JC3 in vivo using a mouse model of Parkinson's disease. ${ }^{33,34}$ In those studies, $10-30 \mu \mathrm{M}$ JC3 was effective in in vitro experiments, whereas mice tolerated JC3 at $10 \mathrm{mg} \mathrm{kg}^{-1}$, administered at 24-h intervals for three consecutive days, or a single administration of JC3 $\left(30 \mathrm{mg} \mathrm{kg}^{-1}\right) \cdot 33,34$ In our present study, we showed that the IFN- $\gamma$-induced increases in IP-10/CXCL10 expression were reduced using $10 \mu \mathrm{M}$ JC3 monomer, $1 \mu \mathrm{M}$ dimer and $0.1 \mu \mathrm{M}$ trimer, those are comparable to doses used previously. ${ }^{33,34}$ However, to evaluate the antiinflammatory activity of JC3 monomer or polymer in vivo, further research and preclinical studies are necessary to ensure the safety of JC3 treatment, and to determine the optimum dose of JC3 for the treatment of TAO.

In summary, our results provide initial evidence that JC3 effectively reduces protein and mRNA expression of IP-10/ CXCL10 induced by IFN- $\gamma$ in orbital fibroblasts cultured from TAO patients. Owing to its ability to modulate pathogenic mechanisms in orbital fibroblasts, JC3 should be considered as a potential candidate for clinical evaluation in the treatment of TAO.

\section{CONFLICT OF INTEREST}

The authors declare no conflict of interest.

\section{ACKNOWLEDGEMENTS}

This work was supported by a National Research Foundation of Korea (NRF) grant funded by the Korean government (MSIP) (Grant 2012R1A5A2A32671866)

1 Pappa A, Lawson JM, Calder V, Fells P, Lightman S. T cells and fibroblasts in affected extraocular muscles in early and late thyroid-associated ophthalmopathy. Br J Ophthalmol 2000; 84: 517-522.

2 Eckstein AK, Quadbeck B, Tews S, Mann K, Kruger C, Mohr CH et al. Thyroid-associated ophthalmopathy: evidence for $\operatorname{CD} 4(+)$ gammadelta $\mathrm{T}$ cells; de novo differentiation of $\operatorname{RFD7}(+)$ macrophages, but not of RFD1 $(+)$ dendritic cells; and loss of gammadelta and alphabeta T cell receptor expression. Br J Ophthalmol 2004; 88: 803-808.

3 Hiromatsu Y, Yang D, Bednarczuk T, Miyake I, Nonaka K, Inoue Y. Cytokine profiles in eye muscle tissue and orbital fat tissue from patients with thyroid-associated ophthalmopathy. J Clin Endocrinol Metab 2000; 85: 1194-1199.

4 Wakelkamp IM, Bakker O, Baldeschi L, Wiersinga WM, Prummel MF. TSH$\mathrm{R}$ expression and cytokine profile in orbital tissue of active vs inactive Graves' ophthalmopathy patients. Clin Endocrinol (Oxf) 2003; 58: 280-287.

5 Bahn RS. Graves' ophthalmopathy. New Eng/ J Med 2010; 362: 726-738.

6 Chen B, Tsui S, Smith TJ. IL-1 beta induces IL-6 expression in human orbital fibroblasts: identification of an anatomic-site specific phenotypic attribute relevant to thyroid-associated ophthalmopathy. J Immunol 2005; 175: 1310-1319.

7 Han R, Tsui S, Smith TJ. Up-regulation of prostaglandin E2 synthesis by interleukin-1 beta in human orbital fibroblasts involves coordinate induction of prostaglandin-endoperoxide $\mathrm{H}$ synthase-2 and glutathione-dependent prostaglandin E2 synthase expression. J Biol Chem 2002; 277: 16355-16364.

8 Koumas L, Smith TJ, Phipps RP. Fibroblast subsets in the human orbit: Thy- $1+$ and Thy-1- subpopulations exhibit distinct phenotypes. Eur $J$ Immunol, 2002; 32: 477-485.

9 Luster AD, Unkeless JC, Ravetch JV. Gamma-interferon transcriptionally regulates an early-response gene containing homology to platelet proteins. Nature 1985; 315: 672-676.

10 Clarke DL, Clifford RL, Jindarat S, Proud D, Pang L, Belvisi M et al. TNFalpha and IFNgamma synergistically enhance transcriptional activation of CXCL10 in human airway smooth muscle cells via STAT-1, NF-kappaB, and the transcriptional coactivator CREB-binding protein. J Biol Chem 2010; 285: 29101-29110. 
$11 \mathrm{Kim}$ HJ, Song DE, Lim SY, Lee SH, Kang JL, Lee SJ et al. Loss of the promyelocytic leukemia protein in gastric cancer: implications for IP-10 expression and tumor-infiltrating lymphocytes. PLOS One 2011; 6: e26264.

12 Saha B, Jyothi Prasanna S, Chandrasekar B, Nandi D. Gene modulation and immunoregulatory roles of interferon gamma. Cytokine 2010; 50: $1-14$.

13 Romero AI, Lagging M, Westin J, Dhillon AP, Dustin LB, Pawlotsky JM et al. Interferon (IFN)-gamma-inducible protein-10: association with histological results, viral kinetics, and outcome during treatment with pegylated IFN-alpha 2a and ribavirin for chronic hepatitis $\mathrm{C}$ virus infection. J Infect Dis 2006; 194: 895-903.

14 Syed Ahamed Kabeer B, Paramasivam P, Raja A. Interferon gamma and interferon gamma inducible protein-10 in detecting tuberculosis infection. J Infect 2012; 64: 573-579.

15 Feferman T, Maiti PK, Berrih-Aknin S, Bismuth J, Bidault J, Fuchs S et al. Overexpression of IFN-induced protein 10 and its receptor CXCR3 in myasthenia gravis. J Immunol 2005; 174: 5324-5331.

16 Nishioji K, Okanoue T, Itoh Y, Narumi S, Sakamoto M, Nakamura H et al. Increase of chemokine interferon-inducible protein-10 (IP-10) in the serum of patients with autoimmune liver diseases and increase of its mRNA expression in hepatocytes. Clin Exp Immunol 2001; 123 271-279.

17 Garcia-Lopez MA, Sancho D, Sanchez-Madrid F, Marazuela M. Thyrocytes from autoimmune thyroid disorders produce the chemokines IP-10 and Mig and attract CXCR3 + lymphocytes. J Clin Endocrinol Metab 2001; 86: 5008-5016.

18 Rotondi M, Chiovato L. The chemokine system as a therapeutic target in autoimmune thyroid diseases: a focus on the interferon-gamma inducible chemokines and their receptor. Curr Pharm Des 2011; 17: 3202-3216.

19 Antonelli A, Rotondi M, Ferrari SM, Fallahi P, Romagnani P, Franceschini SS et al. Interferon-gamma-inducible alpha-chemokine CXCL10 involvement in Graves' ophthalmopathy: modulation by peroxisome proliferator-activated receptor-gamma agonists. J Clin Endocrinol Metab 2006; 91: 614-620.

20 Surh YJ. Anti-tumor promoting potential of selected spice ingredients with antioxidative and anti-inflammatory activities: a short review. Food Chem Toxicol 2002; 40: 1091-1097.

21 Srimal RC, Sharma JN, Tangri AN, Dhawan BN. Experimental evaluation of anti-inflammatory activity of 3,4-dimethoxyphenylethylamino-3-aminopyridine (Compound 64-92). Indian J Exp Biol 1973; 11: 183-187.

22 Chun KS, Sohn Y, Kim HS, Kim OH, Park KK, Lee JM et al. Anti-tumor promoting potential of naturally occurring diarylheptanoids structurally related to curcumin. Mutation Research/Fundamental and Molecular Mechanisms of Mutagenesis 1999; 428: 49-57.

23 Ninomiya $Y$, Shimma N, Ishitsuka H. Comparative studies on the antirhinovirus activity and the mode of action of the rhinovirus capsid binding agents, chalcone amides. Antiviral Res 1990; 13: 61-74.

24 Oh S, Jang S, Kim D, Han IO, Jung JC. Synthesis and evaluation of biological properties of benzylideneacetophenone derivatives. Arch Pharm Res 2006; 29: 469-475.
25 Kim H, Choi YH, Park SJ, Lee SY, Kim SJ, Jou I et al. Antifibrotic effect of Pirfenidone on orbital fibroblasts of patients with thyroid-associated ophthalmopathy by decreasing TIMP-1 and collagen levels. Invest Ophthalmol Vis Sci 2010; 51: 3061-3066.

26 Zhao LQ, Wei RL, Cheng JW, Cai JP, Li Y. The Expression of Intercellular Adhesion Molecule-1 Induced by CD40-CD40L Ligand Signaling in Orbital Fibroblasts in Patients with Graves' Ophthalmopathy. Invest Ophthalmol Vis Sci 2010; 51: 4652.

27 Smith TJ. Orbital fibroblasts exhibit a novel pattern of responses to proinflammatory cytokines: potential basis for the pathogenesis of thyroid-associated ophthalmopathy. Thyroid 2002; 12: 197-203.

28 Epstein FH, Bahn RS, Heufelder AE. Pathogenesis of Graves' ophthalmopathy. N Eng J Med 1993; 329: 1468-1475.

29 Khoo TK, Bahn RS. Pathogenesis of Graves' ophthalmopathy: the role of autoantibodies. Thyroid 2007; 17: 1013-1018.

30 Burch HB, Wartofsky L. Graves' ophthalmopathy: current concepts regarding pathogenesis and management. Endocr Rev 1993; 14: 747-793.

31 Kiuchi F, Iwakami S, Shibuya M, Hanaoka F, Sankawa U. Inhibition of prostaglandin and leukotriene biosynthesis by gingerols and diarylheptanoids. Chem Pharm Bull (Tokyo) 1992; 40: 387-391.

32 Surh YJ, Park KK, Chun KS, Lee LJ, Lee E, Lee SS. Anti-tumor-promoting activities of selected pungent phenolic substances present in ginger. J Environ Pathol Toxicol Oncol 1999; 18: 131-139.

33 Jang $\mathrm{S}$, Jung JC, Kim DH, Ryu JH, Lee $\mathrm{Y}$, Jung $\mathrm{M}$ et al. The neuroprotective effects of benzylideneacetophenone derivatives on excitotoxicity and inflammation via phosphorylated Janus tyrosine kinase 2/phosphorylated signal transducer and activator of transcription 3 and mitogenactivated protein K pathways. J Pharmacol Exp Ther 2009; 328: 435-447.

34 Kang JM, Jung JC, Kim H, Lim H, Jang S, Oh S. Neuroprotective effect of benzylideneacetophenone derivative on the MPTP model of neurodegeneration in mice. Arch Pharm Res 2008; 31: 1098-1107.

35 Spurrell JC, Wiehler S, Zaheer RS, Sanders SP, Proud D. Human airway epithelial cells produce IP-10 (CXCL10) in vitro and in vivo upon rhinovirus infection. Am J Physiol Lung Cell Mol Physiol 2005; 289: L85-L95.

36 Smith TJ, Hegedus L, Douglas RS. Role of insulin-like growth factor-1 (IGF-1) pathway in the pathogenesis of Graves' orbitopathy. Best Pract Res Clin Endocrinol Metab 2012; 26: 291-302.

37 Iyer S, Bahn R. Immunopathogenesis of Graves' ophthalmopathy: the role of the TSH receptor. Best Pract Res Clin Endocrinol Metab 2012; 26: 281-289.

38 Douglas RS, Gupta S. The pathophysiology of thyroid eye disease: implications for immunotherapy. Curr Opin Ophthalmol 2011; 22: 385-390.

$($ (1) $(\Theta)$ This work is licensed under a Creative Commons Attribution-NonCommercial-NoDerivs 3.0 Unported License. To view a copy of this license, visit http:// creativecommons.org/licenses/by-nc-nd/3.0/ 